\title{
Perfectionism: A Brief Review
}

\author{
Mina Khatibi ${ }^{*}$, Mahboobeh Fouladchang ${ }^{2}$
}

\section{ABSTRACT}

What is meant by the words perfectionism? Perfectionism is not necessarily about being perfect. It is the relentless striving for extremely high standards that are personally demanding. Perfectionists are divided into two types, adaptive and maladaptive. It has been found that both adaptive and maladaptive perfectionists have high personal standards, but failing to meet those standards is more stressful for the latter than for the former. Perfectionism is often mistaken for being perfect or doing something perfectly. This review defines perfectionism and identifies both the helpful and the unhelpful aspects of being a perfectionist, and determines in what ways you might be a perfectionist.

Keywords: Perfectionism, Personal Standards, Relentless Striving, Psychology

\section{Perfectionism}

\section{Definition}

Perfectionism is a personality trait characterized by a person's striving for flawlessness and setting excessively high performance standards, accompanied by overly critical self-evaluations and concerns regarding others' evaluations (Stoeber and Childs, 2010 ; Flett and Hewitt, 2002). It is best conceptualized as a multidimensional characteristic, as psychologists agree that there are many positive and negative aspects (Yang and Stoeber, 2012).

\section{Historical Overview}

Why do many researchers find it difficult to accept that perfectionism can be positive?

Traditionally, perfectionism has been associated with psychopathology, with psychodynamic theory stressing that perfectionism was a sign of a neurotic and disordered personality. Even though Hamachek (1978) published his proposal to distinguish two forms of perfectionismnormal perfectionism and neurotic perfectionism — at the end of the 1970's, the dominant view of the 1980's was that perfectionism was always neurotic, dysfunctional, and indicative of psychopathology. Empirical findings supported this view. Studies with clinical populations found elevated levels of perfectionism in clients diagnosed with depression, obsessive-

\footnotetext{
${ }^{1} \mathrm{PhD}$ Student, Department of Educational Psychology, School of Education and Psychology, Shiraz University, Shiraz, Iran

${ }^{2}$ Professor of Educational Psychology, Department of Educational Psychology, School of Education and Psychology, Shiraz University, Shiraz, Iran

*Responding Author

(c) 2016 I M Khatibi, M Fouladchang; licensee IJIP. This is an Open Access Research distributed under the terms of the Creative Commons Attribution License (http://creativecommons.org/licenses/by/2.0), which permits unrestricted use, distribution, and reproduction in any Medium, provided the original work is properly cited.
} 


\section{Perfectionism: A Brief Review}

compulsive disorder, and eating disorders, and studies with nonclinical populations found perfectionism to be related to higher levels of distress and to pathological symptoms associated with depression, anxiety, and disordered eating (Stoeber and Rambow, 2007).

This changed at beginning of the 1990's, when two research groups independently demonstrated that perfectionism is multidimensional in nature, and provided perfectionism research with two multidimensional scales to capture the construct in all its facets (Stoeber and Rambow, 2007). Frost et al. (1990) proposed that six facets in the experience of perfectionism be differentiatedpersonal standards, organization, concern over mistakes, doubts about actions, parental expectations, and parental criticism. Hewitt and Flett (1991) proposed that three facets of perfectionism be differentiated - self-oriented perfectionism, socially prescribed perfectionism, and other-oriented perfectionism.

Frost et al. (1993) made three important contributions. First, they showed that the different facets of perfectionism combined to form two basic dimensions of perfectionism. Second, they showed that these two basic dimensions related to different characteristics. Third, they showed that only the perfectionistic concerns dimension related to negative characteristics whereas the perfectionistic strivings dimension related to positive characteristics-and thus provided first empirical evidence that some forms of perfectionism can be positive.

Hamachek was one of the first psychologists to argue for two distinct types of perfectionism, classifying people as normal perfectionists or neurotic perfectionists. Normal perfectionists pursue perfection without compromising their self-esteem, and derive pleasure from their efforts. Neurotic perfectionists strive for unrealistic goals and consistently feel dissatisfied when they cannot reach them (Hamachek, 1978). Today researchers largely agree that these two basic types of perfectionism are distinct (Rice et al., 2011). They have been labeled differently, and are sometimes referred to as positive striving and maladaptive evaluation concerns, active and passive perfectionism, positive and negative perfectionism, and adaptive and maladaptive perfectionism (Stoeber and Otto, 2006). Although there is a general perfectionism that affects all realms of life, some researchers contend that levels of perfectionism are significantly different across different domains (i.e., work, academic, sport, interpersonal relationships, home life) (Yang and Stoeber, 2012).

Perfectionism consists of two main dimensions: perfectionistic strivings and perfectionistic concerns (Stoeber and Otto, 2006). Perfectionistic strivings are associated with positive aspects of perfectionism; perfectionistic concerns are associated with negative aspects. Healthy perfectionists score high in perfectionistic strivings and low in perfectionistic concerns. Unhealthy perfectionists score high in both strivings and concerns. Nonperfectionists show low levels of perfectionistic strivings (Stoeber and Otto, 2006). Prompted by earlier research providing empirical evidence that perfectionism could be associated with positive aspects (specifically perfectionistic strivings) (Frost et al., 1993), they challenged the widespread belief 


\section{Perfectionism: A Brief Review}

that perfectionism is only detrimental. In fact, people with high levels of perfectionistic strivings and low levels of perfectionist concerns demonstrated more self-esteem, agreeableness, academic success, and social interaction. This type of perfectionist also showed fewer psychological and somatic issues typically associated with perfectionism, namely depression, anxiety, and maladaptive coping styles (Stoeber and Otto, 2006).

\section{Measurements}

\section{Multidimensional Perfectionism Scale (MPS)}

Frost et al. (1990) developed a multidimensional perfectionism scale (now known as the "Frost Multidimensional Perfectionism Scale", FMPS) with six dimensions: concern over making mistakes, high personal standards (striving for excellence), the perception of high parental expectations, the perception of high parental criticism, the doubting of the quality of one's actions, and a preference for order and organization (Frost et al., 1990).

Hewitt and Flett (1991) devised another Multidimensional Perfectionism Scale (MPS), a 45-item measure that rates three aspects of perfectionistic self-presentation: self-oriented perfectionism, other-oriented perfectionism, and socially prescribed perfectionism (Hewitt and Flett, 1991). Self-oriented perfectionism is having irrational expectations and standards for oneself that lead to a perfectionistic motivation. An example is the constant desire to achieve an ideal physical appearance out of vanity.

A similarity has been pointed out among Frost's distinction between setting high standards for oneself and the level of concern over making mistakes in performance (the two most important dimensions of the FMPS) and Hewitt and Flett's distinction between self-oriented versus socially prescribed perfectionism (Taris et al., 2010).

\section{Almost Perfect Scale-Revised (APS-R)}

Slaney and his colleagues (1996) developed the Almost Perfect Scale-Revised (APS-R) to identify perfectionists (adaptive or maladaptive) and non-perfectionists (Slaney et al., 2001). People are classified based on their scores for High Standards, Order, and Discrepancy measures. Both adaptive and maladaptive perfectionists rate highly in High Standards and Order, but maladaptive perfectionists also rate highly in Discrepancy. Discrepancy refers to the belief that personal high standards are not being met, which is the defining negative aspect of perfectionism (Slaney et al., 2001). Maladaptive perfectionists typically yield the highest social stress and anxiety scores, reflecting their feelings of inadequacy and low self-esteem (Rice et al., 2011). In general, the APS-R is a relatively easy instrument to administer, and can be used to identify perfectionist adolescents as well as adults, though it has yet to be proven useful for children (Rice et al., 2011). Interestingly, in one study evaluating APS-R in an adolescent population, maladaptive perfectionists obtained higher satisfaction scores than non-perfectionists. This finding suggests that adolescents' high standards may protect them from challenges to personal satisfaction when their standards are not met (Rice et al., 2011). Two other forms of the APS-R 
measure perfectionism directed towards intimate partners (Dyadic Almost Perfect Scale) and perceived perfectionism from one's family (Family Almost Perfect Scale).

\section{Physical Appearance Perfectionism Scale (PAPS)}

The Physical Appearance Perfectionism Scale (PAPS) explains a particular type of perfectionism - the desire for a perfect physical appearance (Yang and Stoeber, 2012). The PAPS is a multidimensional assessment of physical appearance perfectionism that provides the most insight when the sub-scales are evaluated separately (Yang and Stoeber, 2012). In general, the PAPS allows researchers to determine participants' body image and self-conceptions of their looks, which is critical in present times when so much attention is paid to attractiveness and obtaining the ideal appearance (Yang and Stoeber, 2012). The two sub-scales it uses to assess appearance concerns are Worry About Imperfection and Hope For Perfection. Those that obtain high Worry About Imperfection scores are usually greatly concerned with maladaptive aspects of perfectionism, physical appearance, and body control behavior (Yang and Stoeber, 2012). They also demonstrate low positive self-perceptions of their appearance, whereas those scoring highly on Hope For Perfection yielded high positive self-perceptions (Yang and Stoeber, 2012). Hope For Perfection also corresponded with impression management behaviors and striving for ambitious goals. In sum, Worry About Imperfection relates to negative aspects of appearance perfectionism, while Hope For Perfection relates to positive aspects. One limitation of using the PAPS is the lack of psychological literature evaluating its validity (Yang and Stoeber, 2012).

\section{IMPLICATIONS}

Daniels and Price (2000) refer to perfectionists as "ones". Perfectionists are focused on personal integrity and can be wise, discerning, and inspiring in their quest for the truth. They also tend to dissociate themselves from their flaws or what they believe are flaws (such as negative emotions) and can become hypocritical and hypercritical of others, seeking the illusion of virtue to hide their own vices (Daniels and Price, 2000).

Researchers have begun to investigate the role of perfectionism in various mental disorders such as depression, anxiety, eating disorders, and personality disorders. Each disorder has varying levels of the three measures on the MPS-scale. Socially prescribed perfectionism in young women has been associated with greater body-image dissatisfaction and avoidance of social situations that focus on weight and physical appearance (Hewitt et al., 1995).

The relationship that exists between perfectionistic tendencies and methods of coping with stress has also been examined with some detail. One recent study found that college students with adaptive perfectionistic traits, such as goal fixation or high standards of performance, were more likely to utilize active or problem focused coping (Wielkiewicz and Wonderlich, 2006). Those who displayed maladaptive perfectionistic tendencies, such as rumination over past events or fixation on mistakes, tended to utilize more passive or avoidance coping. Despite these differences, both groups tended to utilize self-criticism as a coping method (Wielkiewicz and 
Wonderlich, 2006). This is consistent with theories that conceptualize self-criticism as a central element of perfectionism (Dunkley et al., 2003).

\section{POSITIVE ASPECTS}

Slaney and his colleagues found that adaptive perfectionists had lower levels of procrastination than non-perfectionists. In the field of positive psychology, an adaptive and healthy variation of perfectionism is referred to as optimalism (Neimark, 2007). Exceptionally talented people who excel in their field sometimes show signs of perfectionism. High-achieving athletes, scientists, and artists often show signs of perfectionism. The adaptive form of perfectionism is typically considered the positive component of this personality trait. Adaptive perfectionism includes preferences for order and organization, a persistent striving for excellence, and conscientious orientation to tasks and performance (Rice et al., 2007). All of these characteristics are accompanied by low criticism and negativity, and high support and self-esteem (Rice et al., 2007). The positive, adaptive forms of perfectionism are more closely associated with the Big Five personality factor of conscientiousness, whereas maladaptive forms are more similar to neuroticism (Rice et al., 2007).

Perfectionism often shows up in performance at work or school, neatness and aesthetics, organization, writing, speaking, physical appearance, and health and personal cleanliness.

Maladaptive perfectionism is more similar to neuroticism while adaptive perfectionism is more similar to conscientiousness. The latter positively corresponds with life satisfaction, self-esteem, secure attachment, and cohesive self-development (Rice et al., 2007).

\section{CONCLUSION AND RECOMMENDATIONS}

In its positive form, perfectionism can drive people to accomplishments and provide the motivation to persevere in the face of discouragement and obstacles. In a positive form, perfectionism can provide the driving energy which leads to great achievement.

In its negative form, perfectionism can be damaging. In general, maladaptive perfectionists feel constant pressure to meet their high standards, which creates cognitive dissonance when they cannot meet their own expectations.

Perfectionism is often mistaken for being perfect or doing something perfectly. This review defines perfectionism and identifies both the helpful and the unhelpful aspects of being a perfectionist, and determines in what ways you might be a perfectionist.

Therefore, it is recommended to consider both aspects of perfectionism with special attention on positive aspects. 


\section{REFERENCES}

Antony M. (2009). When Perfect Isn't Good Enough: Strategies for Coping with Perfectionism. Oakland, CA: New Harbinger Publications, p. 312.

Briggs SR, Cheek JM. (1986). The role of factor analysis in the development and evaluation of personality scales. Journal of Personality, 54 (1): 106-148.

Cattell H, Mead A. (2008). The Sixteen Personality Factor Questionnaire (16PF). The SAGE Handbook of Personality Theory and Assessment, 2: 135-159.

Daniels D, Price V. (2000). The Essential Enneagram. New York: Harper Collins. Dunkley DM, Blankstein KR, Masheb RM, Grilo CM. (2006). Personal standards and evaluative concerns dimensions of "clinical” perfectionism: A reply to Shafran et al. (2002, 2003) and Hewitt et al. (2003). Behaviour Research and Therapy, 44: 63-84.

Dunkley DM, Zuroffd C, Blanksteikn R. (2003). Self-critical perfectionism and daily affect: Dispositional and situational influences on stress and coping. Journal of Personality and Social Psychology, 84: 234-252.

Flett GL, Hewitt PL. (2002). Perfectionism. Washington, DC: American Psychological Association, pp. 5-31.

Frost RO, Heimburg RG, Holt CS, Mattia JI, Neubauer AA. (1993). A comparison of two measures of perfectionism. Personality and Individual Differences, 14: 469-489.

Frost RO, Marten P, Lahart C, Rosenblate R. (1990). The dimensions of perfectionism. Cognitive Therapy and Research, 14 (5): 449-468.

Greenberg J. (2008). Understanding the vital human quest for self-esteem. Perspectives on Psychological Science, 3 (1): 48-55.

Hamachek DE. (1978). Psychodynamics of normal and neurotic perfectionism. Psychology, 15: 27-33.

Haney P, Durlak JA. (1998). Changing self-esteem in children and adolescents. A meta- analytic review. Journal of Clinical Child Psychology, 27: 423-433.

Hewitt PL, Flett G, Ediger E. (1995). Perfectionism traits and perfectionistic self-presentation in eating disorder attitudes, characteristics, and symptoms. International Journal of Eating Disorders, 18 (4): 317-326.

Hewitt PL, Flett G. (1991). Dimensions of perfectionism in unipolar depression". Journal of Abnormal Psychology, 100 (1): 98-101.

Neimark J. (2007). "The Optimism Revolution". Psychology Today, 1-3. Retrieved July 1, 2011.

Rice KG, Ashby JS, Gilman R. (2011). Classifying adolescent perfectionists. Psychological Assessment, 23 (3): 563-577.

Rice KG, Leever BA, Noggle CA, Lapsley DK. (2007). Perfectionism and depressive symptoms in early adolescence. Psychology in the Schools, 44 (2): 139-156.

Slaney RB, Rice KG, Mobley M, Trippi J, Ashby JS. (2001). The Revised Almost Perfect Scale. Measurement and Evaluation in Counseling and Development, 34 (3): 130-145.

Stoeber J, Childs JH. (2010). The assessment of self-oriented and socially prescribed perfectionism: Subscales make a difference. Journal of Personality Assessment, 92 (6): 577-585. 
Stoeber J, Otto K. (2006). Positive conceptions of perfectionism: Approaches, evidence, challenges. Personality and Social Psychology Review, 10 (4): 295-319.

Stoeber J, Rambow A. (2007). Perfectionism in adolescent school students: Relations with motivation, achievement, and well-being. Personality and Individual Differences, 42 (7): 1379-1389.

Taris TW, van Beek I, Schaufeli WB. (2010). Why do perfectionists have a higher burnout risk than others? The mediational effect of workaholism. Romanian Journal of Applied Psychology, 12 (1): 1-7.

Wielkiewicz RM, Wonderlich SJ. (2006). Correlations between perfectionism and coping strategies in response to researcher-selected vignettes or participant-selected events. Psychological Reports, 98(3): 745-755.

Yang H, Stoeber J. (2012). The physical appearance perfectionism scale: Development and preliminary validation. Journal of Psychopathology and Behavioral Assessment, 34 (1): 69-83.

How to cite this article: M Khatibi, M Fouladchang (2016), Perfectionism: A Brief Review, International Journal of Indian Psychology, Volume 3, Issue 3, No. 8, DIP: 18.01.135/20160303, ISBN: 978-1-365-12176-0 